\title{
ARTICLE
}

Received 18 Jun 2014 | Accepted 22 Sep 2014 | Published 4 Nov $2014 \quad$ DOl: 10.1038/ncomms6353

\section{A heavy analogue of the smallest bridgehead alkene stabilized by a base}

Takeaki Iwamoto ${ }^{1}$, Naohiko Akasaka ${ }^{1} \&$ Shintaro Ishida ${ }^{1}$

Bicyclo[1.1.0]but-1(2)-ene (BBE), one of the smallest bridgehead alkenes and $\mathrm{C}_{4} \mathrm{H}_{4}$ isomers, exists theoretically as a reactive intermediate, but has not been observed experimentally. Here we successfully synthesize the silicon analogue of BBE, tetrasilabicyclo[1.1.0]but-1(2)ene $\left(\mathrm{Si}_{4} \mathrm{BBE}\right)$, in a base-stabilized form. The results of $\mathrm{X}$-ray diffraction analysis and theoretical study indicate that $\mathrm{Si}_{4} \mathrm{BBE}$ predominantly exists as a zwitterionic structure involving a tetrasilahomocyclopropenylium cation and a silyl anion rather than a bicyclic structure with a localized highly strained double bond. The reaction of base-stabilized $\mathrm{Si}_{4} \mathrm{BBE}$ with triphenylborane affords the $[2+2]$ cycloadduct of $\mathrm{Si}_{4} \mathrm{BBE}$ and the dimer of an isomer of $\mathrm{Si}_{4} \mathrm{BBE}$, tetrasilabicyclo[1.1.0]butan-2-ylidene ( $\mathrm{Si}_{4} \mathrm{BBY}$ ). The facile isomerization between $\mathrm{Si}_{4} \mathrm{BBE}$ and $\mathrm{Si}_{4} \mathrm{BBY}$ is supported by theoretical calculations and trapping reactions. Structure and properties of a heavy analogue of the smallest bridgehead alkene are disclosed.

\footnotetext{
${ }^{1}$ Department of Chemistry, Graduate School of Science, Tohoku University, 6-3 Aramakiazaaoba, Aoba-ku, Sendai 980-8578, Japan. Correspondence and requests for materials should be addressed to T.I. (email: iwamoto@m.tohoku.ac.jp).
} 
B ridgehead alkenes have a strained doubly bonded carbon at the bridgehead positions in the bicyclic skeleton. Their syntheses, highly strained structures and high reactivities have widely attracted the attention of both theoretical and experimental chemists since the pioneering work of Bredt ${ }^{1-5}$. Bicyclo[1.1.0]but-1(2)-ene (BBE, E=C, Fig. 1a) is a bridgehead alkene with the smallest number of bridge atoms and several possible canonical structures containing a strained double bond ${ }^{2}$, even though $\mathrm{BBE}$ has been considered to be an exceptional bridgehead alkene ('zero-bridge alkene') because of the lack of a twisted double-bond geometry observed in typical bridgehead alkenes. Although BBE and its derivatives have been proposed as reactive intermediates ${ }^{6}$ and theoretically investigated as the isomers of $\mathrm{C}_{4} \mathrm{H}_{4}$ molecules present in important fundamental organic molecules such as tetrahedrane and cyclobutadiene ${ }^{7-11}$, the synthesis and experimental observation of BBE and its derivatives have not been reported yet.

Recently, the silicon analogues of alkenes and structurally related unsaturated organic compounds that have never been experimentally observed or synthesized previously such as pentasilaspiropentadiene ${ }^{12}$, tetrasilacyclobutadiene with a planar rhombic charge-separated structure ${ }^{13}$, trisilavinylcarbene ${ }^{14}$, silavinylidene $\mathrm{e}^{15}, \quad \mathrm{Si}(0)_{2} \quad$ (ref. 16) and isomers of hexasilabenzene ${ }^{17,18}$ have been synthesized as isolable molecules by taking advantage of kinetic stabilization and/or stabilization by base coordination. Their structures and properties have contributed to further understanding of the bonding and structures of organic and heavy main group element $\pi$-electron compounds. Among the $\mathrm{Si}_{4} \mathrm{R}_{4}$ species, tetrasilatetrahedrane ${ }^{19}$ and tetrasilacylobutadiene ${ }^{13}$ have been isolated. However, the tetrasila version of $\mathrm{BBE}\left(\mathrm{Si}_{4} \mathrm{BBE}, \mathrm{E}=\mathrm{Si}\right.$, Fig. 1a) has been only theoretically investigated as one of the isomers among the $\mathrm{Si}_{4} \mathrm{R}_{4}$ molecules ${ }^{20,21}$, whereas it's detailed molecular and electronic structures and reactivity remain elusive.

In this study we report the synthesis of $\mathrm{Si}_{4} \mathrm{BBE} \mathbf{1}$, which was stabilized by coordinating to 4 -(N,N-dimethylamino)pyridine (DMAP) (1-DMAP). The results of X-ray diffraction (XRD) analysis and theoretical study indicate that $\mathrm{Si}_{4} \mathrm{BBE}$ predominantly exists as a zwitterionic structure containing a tetrasilahomocyclopropenylium cation $^{22}$ and a silyl anion, rather than a bicyclic structure with a localized double bond. The elimination of DMAP from 1.DMAP with $\mathrm{BPh}_{3}$ afforded the $[2+2]$ cycloadduct of 1 (4) and the dimer of tetrasilabicyclo[1.1.0]butan-2-ylidene $\left(\mathrm{Si}_{4} \mathrm{BBY}\right) \mathbf{1}^{\prime}(\mathbf{8})$, whose parent molecule was predicted as the global minimum on a $\mathrm{Si}_{4} \mathrm{H}_{4}$ surface ${ }^{20,21}$. These results indicate a reversible valence isomerization between $\mathbf{1}$ and $\mathbf{1}^{\prime}$, which was supported by the thermal isomerization of $\mathbf{8}$ to $\mathbf{4}$ and reactions of 8 with $\mathrm{SiCl}_{4}$ and DMAP. Thus, the synthesis, structure, bonding and reactivity of a heavy analogue of the smallest bridgehead alkenes are reported.

a

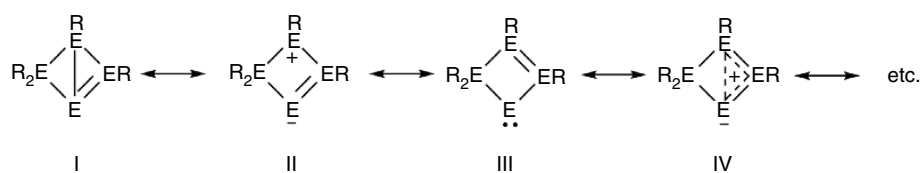

Bicyclo[1.1.0]but-1(2)-ene (BBE, E = C)

Tetrasilabicyclo[1.1.0]but-1(2)-ene $\left(\mathrm{Si}_{4} \mathrm{BBE}, \mathrm{E}=\mathrm{Si}\right)$

b
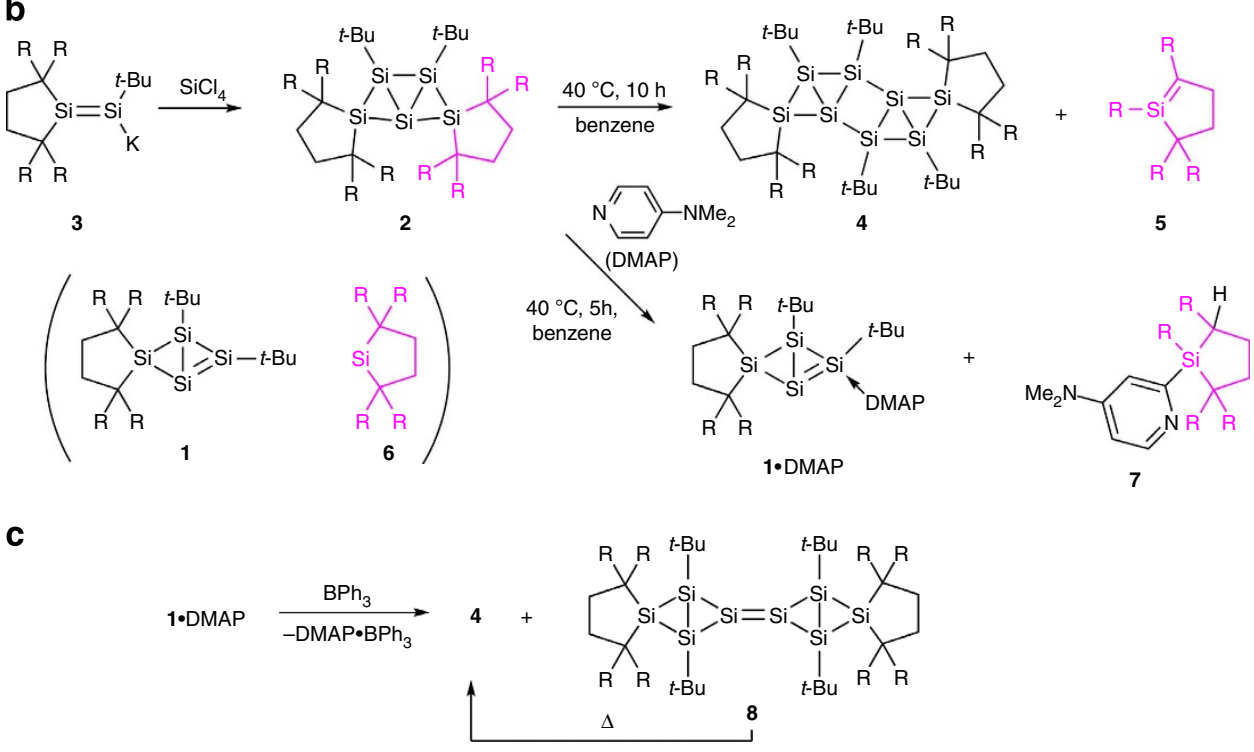

d

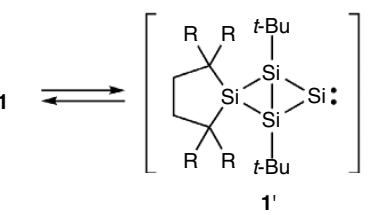

e

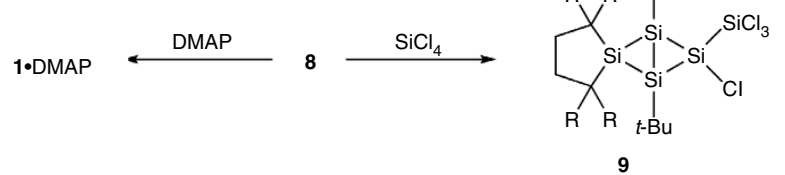

Figure 1 | Synthesis and reactions of a silicon analogue of the smallest bridgehead alkene. (a) $B B E$ and its silicon analogue ( $\mathrm{Si}_{4} \mathrm{BBE}$ ). (b) $\mathrm{Synthesis}$ of DMAP-stabilized $\mathrm{Si}_{4} \mathrm{BEE}(\mathbf{1} \cdot \mathrm{DMAP})\left(\mathrm{R}=\mathrm{SiMe}_{3}\right)$ and the dimer of $\mathrm{Si}_{4} \mathrm{BBE}(\mathbf{4})$. (c) Reaction of $\mathbf{1} \cdot \mathrm{DMAP}$ with triphenylborane $\left(\mathrm{R}=\mathrm{SiMe} \mathrm{e}_{3}\right)$. $(\mathbf{d}) \mathrm{A}$ possible equilibrium between $\mathrm{Si}_{4} \mathrm{BBE} \mathbf{1}$ and tetrasilabicyclo[1.1.0]butan-2-ylidene $\left(\mathrm{Si}_{4} \mathrm{BBY}\right) \mathbf{1}^{\prime}\left(\mathrm{R}=\mathrm{SiMe}_{3}\right)$. (e) Reactions of disilene 8 supporting generation of $\mathbf{1}$ and $\mathbf{1}^{\prime}\left(\mathrm{R}=\mathrm{SiMe}_{3}\right)$. 


\section{Results}

Thermolysis of hexaalkyltricyclo[2.1.0.0 $\left.{ }^{1,3}\right]$ pentasilane. $\mathrm{Si}_{4} \mathrm{BBE}$ 1 was initially suggested to be generated by the thermolysis of hexaalkyltricyclo[2.1.0.0 $0^{1,3}$ ]pentasilane 2 , which was prepared in $63 \%$ yield by the reaction of the corresponding potassium trialkyldisilenide 3 (ref. 23) with 0.5 equiv. of $\mathrm{SiCl}_{4}$ (Figs $1 \mathrm{~b}$ and $2 \mathrm{a}$; for the detailed molecular structure of 2 , see Supplementary Information), similar to the synthesis of Scheschkewitz's hexaaryl derivative $\mathrm{Tip}_{6} \mathrm{Si}_{5} \mathbf{2}^{\prime} \quad(\mathrm{Tip}=2,4,6$ triisopropylphenyl) ${ }^{24}$. Compound $\mathbf{2}$ was isolated as reddish purple crystals at ambient temperature. However, heating 2 at $40^{\circ} \mathrm{C}$ for $10 \mathrm{~h}$ in benzene afforded a mixture of pentacyclo[5.1.0.0 $0^{1,6} \cdot 0^{2,5} \cdot 0^{3,5}$ ] octasilane 4 and silene 5 (Fig. 1b), whereas Scheschkewitz ${ }^{24}$ observed an ion peak assignable to a cluster expansion product with formula $\mathrm{Si}_{7} \mathrm{R}_{6}$ during the measurement of the electron ionization mass spectrometry of $2^{\prime}$. Compound 4 was isolated as orange crystals in $61 \%$ yield and identified by nuclear magnetic resonance (NMR) spectroscopy, mass spectrometry (MS), XRD analysis and elemental analysis (Fig. 2b). The results of XRD analysis indicate that the silicon skeleton of $\mathbf{4}$ has a four-membered ring fused by two tetrasilabicyclo[1.1.0]butane units in a syn manner, which is a formal head-to-tail $[2+2]$ cycloadduct of 1 . Notably, the geometry around naked silicon atoms (silicon atoms without substituents), $\mathrm{Si} 3$ and $\mathrm{Si} 6$ atoms, in 4 are very far from the tetrahedral geometry similar to the naked silicon atoms in $\mathbf{2}$ and $2^{\prime}$ : For $\mathrm{Si} 3$ atom, the angles $\mathrm{Si} 1-\mathrm{Si} 3-\mathrm{Si} 2, \mathrm{Si} 2-\mathrm{Si} 3-\mathrm{Si} 4$, $\mathrm{Si} 4-\mathrm{Si} 3-\mathrm{Si} 5$ and $\mathrm{Si} 1-\mathrm{Si} 3-\mathrm{Si} 5$ are $60.98(3)^{\circ}, 57.22(3)^{\circ}$, $94.29(4)^{\circ}$ and $163.97(4)^{\circ}$, respectively, and for Si6 atom, the angles $\mathrm{Si} 4-\mathrm{Si} 6-\mathrm{Si} 5, \mathrm{Si} 5-\mathrm{Si} 6-\mathrm{Si} 7, \mathrm{Si} 7-\mathrm{Si} 6-\mathrm{Si} 8$ and $\mathrm{Si} 4-\mathrm{Si} 6-\mathrm{Si} 8$ are $94.81(4)^{\circ}, 57.08(3)^{\circ}, 60.08(3)^{\circ}$ and $162.26(4)^{\circ}$, respectively. The transannular $\mathrm{Si} 2-\mathrm{Si} 3$ and $\mathrm{Si} 6-\mathrm{Si} 7$ bond distances in the terminal tetrasilabicyclo[1.1.0]butane units, 2.4067(11) and $2.4177(11) \AA$, respectively, are within the range of $\mathrm{Si}-\mathrm{Si}$ single bond distances. The ${ }^{29} \mathrm{Si}$ chemical shifts of the naked $\mathrm{Si}$, two
( $t$-Bu)Si and $\mathrm{R}_{2}^{\mathrm{H}} \mathrm{Si}$ nuclei $\left(\mathrm{R}_{2}^{\mathrm{H}}=1,1,4,4\right.$-tetrakis(trimethylsilyl) butan-1,4-diyl) are $\delta-26.8$, ( -18.4 and -5.5$)$ and 24.6 p.p.m., respectively. As $\mathbf{5}$ is a thermal isomerization product of dialkylsilylene $\mathbf{6}$ (ref. 25), the generation of $\mathbf{1}$ and $\mathbf{6}$ was indicated by the thermolysis of 2 .

Synthesis of $1 \cdot$ DMAP. To obtain monomeric $\mathrm{Si}_{4} \mathrm{BBE} \mathbf{1}$, we investigated the thermolysis reaction in the presence of a Lewis base, because coordinating to a Lewis base may stabilize $\mathrm{Si}_{4} \mathrm{BBE} \mathbf{1}$, similar to other unsaturated silicon compounds ${ }^{14-16,26}$. The reaction of 2 in the presence of 7.6 equiv. of DMAP, which is a typical Lewis base for unsaturated silicon compounds, at $40^{\circ} \mathrm{C}$ for $5 \mathrm{~h}$ afforded an orange solution. The ${ }^{1} \mathrm{H}$ NMR spectrum of the mixture indicated the existence of a new compound with $\mathbf{1}$ and DMAP units together, and 2-silyl-( $N, N$-dimethylamino)pyridine 7, which is a product of the reaction of silene $\mathbf{5}$ with DMAP. Removal of the volatiles from the reaction mixture and repeated recrystallization from hexane at $-35^{\circ} \mathrm{C}$ and then from benzene at room temperature afforded analytically pure 1.DMAP as orange crystals in $89 \%$ yield. The structure of $\mathbf{1}$.DMAP was determined by NMR spectroscopy, MS spectrometry, XRD analysis and elemental analysis.

X-ray analysis of 1 DMAP. The results of the XRD analysis of 1.DMAP indicate that the central $\mathrm{Si}_{4}$ ring has a folded structure with the dihedral angle Si2-Si1-Si3-Si4 of $127.03(2)^{\circ}$ (Fig. 2c). The nitrogen atom of DMAP coordinates to $\mathrm{Si} 2$ atom with the $\mathrm{Si} 2-\mathrm{N} 1$ distance of $1.8764(14) \AA$, which is moderately longer than the typical $\mathrm{Si}-\mathrm{N}$ distance $(1.71-1.74 \AA)^{27}$. The Sil atom has no substituent and the $\mathrm{Si} 1-\mathrm{Si} 3$ distance is $2.6215(6) \AA$, which is considerably longer than those of known tetrasilabicyclo[1.1.0]butanes $(2.367-2.412 \AA)^{28,29}$, but still shorter than the longest $\mathrm{Si}-\mathrm{Si}$ distance reported so far $\left(2.697 \AA \text { for }(t-\mathrm{Bu})_{3} \operatorname{SiSi}(t-\mathrm{Bu})_{3}\right)^{30}$. The endocyclic $\mathrm{Si} 1-\mathrm{Si} 2$ and a

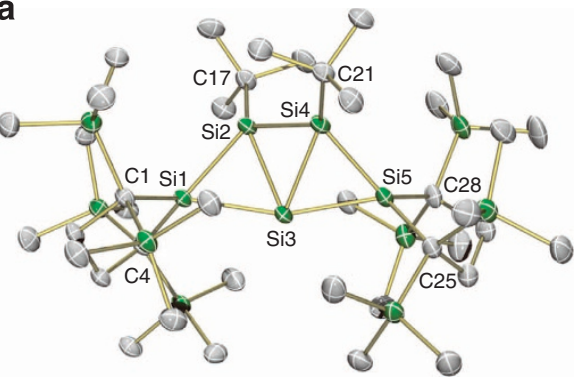

C

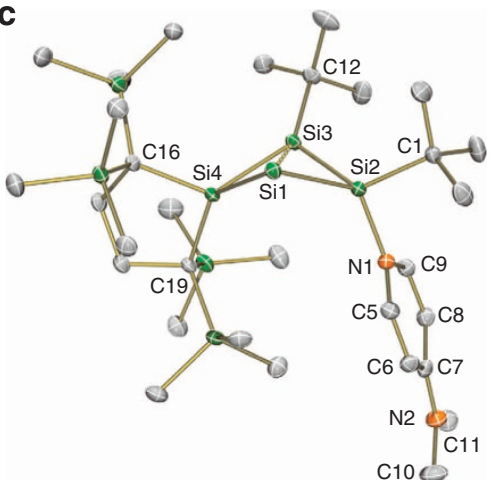

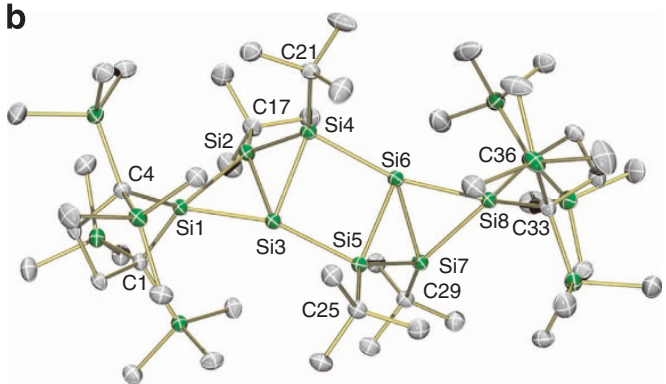

d

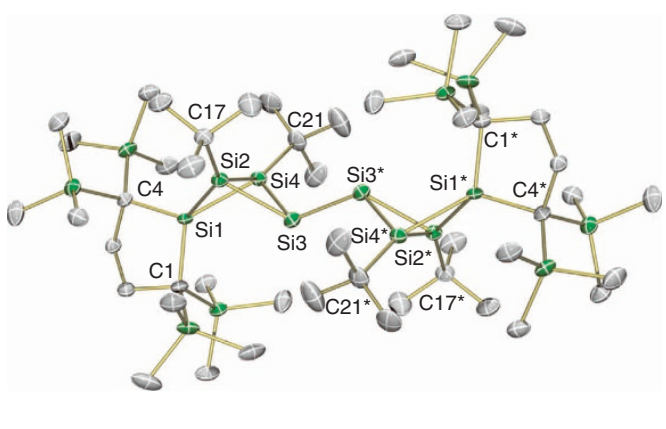

Figure 2 | Molecular structures of 1.DMAP and related compounds as determined by XRD analyses. (a) Tricyclo[2.1.0.01,3]pentasilane 2.

(b) Pentacyclo[5.1.0.0 $0^{1,6} \cdot 0^{2,5} \cdot 0^{3,5}$ ] octasilane 4 (a dimer of $\mathrm{Si}_{4} \mathrm{BBE}$ 1). (c) DMAP-coordinate $\mathrm{Si}_{4} \mathrm{BBE}$ 1.DMAP. (d) Bi(tetrasilabicyclo[1.1.0]butan-2-ylidene) 8 (a dimer of $\mathrm{Si}_{4} \mathrm{BBY} \mathbf{1}^{\prime}$ ). Thermal ellipsoids are shown at the $50 \%$ probability level. Hydrogen atoms are omitted for clarity. 
Si2-Si3 bond distances, 2.2906(6) and 2.2556(6) Å, respectively, are between the typical $\mathrm{Si}-\mathrm{Si}(\text { ca. } 2.36 \AA)^{27}$ and $\mathrm{Si}=\mathrm{Si}$ bond distances $(2.118-2.289 \AA)^{31,32}$, and close to those of $\mathrm{N}$-heterocyclic carbene-coordinated cyclotrisilene (trisilacyclopropene) $(2.2700(5) \AA)^{26}$, indicating a significant double-bond character in $\mathrm{Si} 1-\mathrm{Si} 2$ and $\mathrm{Si} 2-\mathrm{Si} 3$ bonds. The geometry around $\mathrm{Si} 2$ is considerably pyramidalized with the sum of bond angles around $\mathrm{Si} 2$ (except the angles involving $\mathrm{Si} 2-\mathrm{N} 1$ bond) of $312.63(4)^{\circ}$, whereas that around $\mathrm{Si} 3$ is almost planar with the sum of bond angles around $\mathrm{Si} 3$ (except the bond angles involving Sil - Si3 bond), $359.30(4)^{\circ}$. The DMAP moiety exhibits a significant quinoid character. The $\mathrm{C} 5-\mathrm{C} 6, \mathrm{C} 8-\mathrm{C} 9$ and C7 - N2 bond distances are 1.362(2), 1.359(2) and 1.343(2) $\AA$, respectively, which are shorter than those of the corresponding bonds in free DMAP (1.375(4), 1.381(3) and 1.367(3) A), whereas the other $\mathrm{C}-\mathrm{C}$ and $\mathrm{C}-\mathrm{N}$ bond distances (1.418(2)-1.419(2) and $1.358(2)-1.361(2) \AA$, respectively) in the pyridine ring of 1.DMAP are longer than those of free DMAP (1.403(3)-1.404(3) and $1.335(4)-1.337(3) \AA$, respectively) ${ }^{33}$.

Theoretical study of 1 - DMAP and base-free 1 . The comparison of the structural parameters and orbitals between 1.DMAP and base-free 1 obtained by the density functional theory calculations provided further insight into the bonding and structure of 1.DMAP and 1. The structure of 1.DMAP determined by XRD analysis was well reproduced by the optimized structure of 1.DMAP calculated at the M06-2X/6-31G(d) level (1.DMAP ${ }_{\text {opt }}$ ) (see Supplementary Fig. 40). The dihedral angle, Si2-Si1 $\mathrm{Si} 3-\mathrm{Si} 4$, of $1 \cdot \mathrm{DMAP}_{\text {opt }}$ is $124.72^{\circ}$, and the Si1 - Si2, Si2 - Si3, Si1 - Si3 and Si1 - N1 bond distances are 2.2865, 2.2441, 2.6174 and $1.9368 \AA$, respectively, which are very close to those of 1.DMAP. The structural parameters of base-free 1 optimized at the same level $\left(\mathbf{1}_{\text {opt }}\right)$ slightly deviated from those of $\mathbf{1} \cdot \mathrm{DMAP}_{\mathrm{opt}}$ (Fig. 3a). Similar to 1-DMAP, the four-membered ring of $\mathbf{1}_{\mathrm{opt}}$ is folded with the dihedral angle $\mathrm{Si} 4-\mathrm{Si} 1-\mathrm{Si} 3-\mathrm{Si} 2$ of $121.89^{\circ}$.

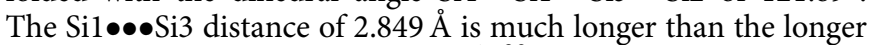
end of $\mathrm{Si}-\mathrm{Si}$ single bond $(2.697 \AA)^{30}$ and that of $1 \cdot \mathrm{DMAP}_{\text {opt }}$ $(2.620 \AA)$. The endocyclic Si1 - Si2 and Si2 - Si3 bond distances of 2.228 and $2.207 \AA$ in $\mathbf{1}_{\text {opt }}$, respectively, are within the range of $\mathrm{Si}=\mathrm{Si}$ double bond $(2.118-2.289 \AA)^{31,32}$ and shorter than those of $1 \cdot \mathrm{DMAP}_{\text {opt }}(2.286$ and $2.244 \AA)$. The bond angle around the unsubstituted $\mathrm{Si} 1$ atom $(\mathrm{Si} 4-\mathrm{Si} 1-\mathrm{Si} 2)$ is $85.2^{\circ}$. The geometries around $\mathrm{Si} 2$ and $\mathrm{Si} 3$ atoms are slightly pyramidalized with the sums of bond angles of $350.24^{\circ}$ and $354.98^{\circ}$, respectively. These results indicate that on the coordination of DMAP, the Si1 - Si2 and $\mathrm{Si} 2-\mathrm{Si} 3$ bond distances of 1 were elongated (2.286 and $2.244 \AA$ ), whereas the Si1 - Si3 bond distance was shortened $(2.620 \AA)$. A similar elongation of $\mathrm{Si}=\mathrm{Si}$ double bonds on the coordination of Lewis bases has been reported by Scheschkewitz et al. ${ }^{26}$

The frontier orbitals of $\mathbf{1}_{\mathrm{opt}}$ and $\mathbf{1} \cdot \mathrm{DMAP}_{\mathrm{opt}}$ are shown in Fig. 3b,c. The highest occupied molecular orbital (HOMO) of $\mathbf{1}_{\mathrm{opt}}$ is a lone pair orbital on Sil with the contribution of a $p$-type orbital on Si3 atom (Fig. 3b), which is close to the orbital feature of the interbridgehead bond proposed for all-carbon bicyclo[1.1.0]but-1(2)ene ${ }^{7}$. The HOMO-1 orbital of $\mathbf{1}$ is an in-phase combination of $\pi(\mathrm{Si} 1-\mathrm{Si} 2)$ orbital and a $p$-type orbital on $\mathrm{Si} 3$ atom. The lowest unoccupied molecular orbital (LUMO) of $\mathbf{1}_{\text {opt }}$ is an out-of-phase combination of $\pi^{\star}(\mathrm{Si} 1-\mathrm{Si} 2)$ orbital and a $p$-type orbital on $\mathrm{Si} 3$ atom, and the LUMO +1 is an anti-bonding orbital between $\mathrm{Si} 1$ and $\mathrm{Si} 3$ atoms. The HOMO-1, LUMO and LUMO +1 orbitals resemble the frontier orbitals of those of tetrasilahomocyclopropenylium cation reported by Sekiguchi et al. ${ }^{22,34}$ These orbital features indicate that the zwitterionic resonance structure with tetrasilahomocyclopropenylium cation over the Si1-Si2-Si3 atom, and silyl anion on Si1 atoms $\left(\mathbf{1}_{\mathbf{z}}\right.$, Fig. 3d) contributes significantly to the electronic structure of $\mathbf{1}_{\text {opt }}$. Very recently, a zwitterionic trisilahomoconjugative compound, a disilaoxaallyl zwitterion was reported by Scheschekwitz et al. ${ }^{35}$ The Wiberg bond indices (WBI) of the $\mathrm{Si} 1-\mathrm{Si} 2$ and $\mathrm{Si} 2-\mathrm{Si} 3$ bonds of $\mathbf{1}_{\mathrm{opt}}$ are 1.34 and 1.34 , respectively, which are larger than those of $\mathrm{Si} 3-\mathrm{Si} 4$ (1.02) and $\mathrm{Si} 4-\mathrm{Si} 1$ (0.88), respectively, whereas the WBI of Si1 - Si3 bond is 0.51 , indicating significant bonding interactions between the bridgehead silicon atoms, Sil and Si3. The natural bonding orbital analysis of $\mathbf{1}_{\mathrm{opt}}$ predicts a three-centred two-electron bond involving Sil (28.3\%), Si2 (35.8\%) and Si3 (35.8\%) with 1.84 electron and a lone pair on Sil with 1.88 electron. These results are consistent with the resonance structure of $\mathbf{1}_{\mathbf{z}}$. The natural population analysis charges of $\mathrm{Si} 1, \mathrm{Si} 2$ and $\mathrm{Si} 3$ atoms are -0.02 , +0.43 and +0.42 , respectively, indicating that $\mathrm{Si} 1-\mathrm{Si} 2$ bond is considerably polar, which is consistent with the formation of head-to-tail cycloadduct 4 . The coordination of DMAP on the Si2 atom of 1 can be rationalized by the positive charge on $\mathrm{Si} 2$ and sterically less congested geometry around Si2 compared with those around $\mathrm{Si} 3$, indicating that a canonical structure involving disilenylsilylene such as the III of $\mathrm{Si}_{4} \mathrm{BBE}$ in Fig. $1 \mathrm{a}$ is a less important contributor. Recently, Scheschkewitz and colleagues ${ }^{14}$ reported a base-stabilized disilenylsilylene in which the base coordinates to the two-coordinate silylene centre. At the M06-2X/ 6-31G(d) level, the coordination of DMAP to $\mathbf{1}_{\mathrm{opt}}$ affording 1. DMAP $_{\text {opt }}$ was calculated to be exergonic at $298 \mathrm{~K}$ $\left(\Delta G_{298 \mathrm{~K}}=-39.4 \mathrm{~kJ} \mathrm{~mol}^{-1}\right)$, which is consistent with the experimental observation. The feature of the frontier orbitals of 1. DMAP ${ }_{\text {opt }}$ resembles to that of $\mathbf{1}_{\text {opt }}$ (Fig. 3c). The WBI of the $\mathrm{Si} 1-\mathrm{Si} 3$ for $\mathbf{1} \cdot \mathrm{DMAP}_{\mathrm{opt}}(0.73)$ is larger than that for $\mathbf{1}_{\mathrm{opt}}(0.51)$, whereas those of the $\mathrm{Si} 1-\mathrm{Si} 2$ and $\mathrm{Si} 2-\mathrm{Si} 3$ for $\mathbf{1} \cdot \mathrm{DMAP}_{\text {opt }}(1.10$ and 1.15) are smaller than those for $\mathbf{1}_{\mathrm{opt}}$ (1.34 and 1.34). The structural change on the coordination of DMAP can be rationalized by the interactions between the lone pair orbital of nitrogen in DMAP and the LUMO of $\mathbf{1}_{\text {opt }}$ involving the bonding interactions between Sil and Si3, and the anti-bonding interactions between $\mathrm{Si} 1$ and $\mathrm{Si} 2$, and between $\mathrm{Si} 2$ and $\mathrm{Si} 3$, resulting in a $\mathrm{LUMO}+3$ orbital.

${ }^{29}$ Si NMR spectra of 1 - DMAP. In benzene- $d_{6}$, three ${ }^{29} \mathrm{Si}$ resonances arising due to the ring silicon nuclei of $\mathbf{1}$.DMAP appeared at $\delta+84.5$, +13.3 and -79.8 p.p.m., which were assigned to $\mathrm{Si}(t-\mathrm{Bu})(\mathrm{DMAP}), \quad \mathrm{SiR}^{\mathrm{H}}{ }_{2}$ and $\mathrm{Si}(t-\mathrm{Bu})$ silicon nuclei by $2 \mathrm{D}^{1} \mathrm{H}_{-}{ }^{29} \mathrm{Si}$ NMR HETCOR experiments. No resonance assignable to the naked silicon nuclei was observed probably because of the considerably long relaxation time of the ${ }^{29} \mathrm{Si}$ nuclei. The assignment of the ${ }^{29} \mathrm{Si}$ resonances are supported by the density functional theory calculations of $\mathbf{1} \cdot \mathrm{DMAP}_{\mathrm{opt}}(+84.4$ $(\underline{\mathrm{i}}(t-\mathrm{Bu})(\mathrm{DMAP})),-4.1\left(\mathrm{SiR}_{2}^{\mathrm{H}}\right)$ and $\left.-105.1(\mathrm{Si}(t-\mathrm{Bu}))\right)$ and the predicted ${ }^{29} \mathrm{Si}$ chemical shift of the naked silicon is $\delta-108.6$ p.p.m. These ${ }^{29} \mathrm{Si}$ resonances indicate that $1 \cdot \mathrm{DMAP}$ adopts a structure similar to that observed in the solid state.

Elimination of DMAP from 1.DMAP. The elimination of DMAP from 1-DMAP was investigated to generate free $\mathrm{Si}_{4} \mathrm{BBE} 1$. When a benzene- $d_{6}$ solution of 1.DMAP was treated with $\mathrm{BPh}_{3}$ at room temperature, the colour of the reaction mixture became green, and the NMR spectrum of the mixture indicated the formation of 4 (72\% yield) and a disilene with two tetrasilabicyclo[1.1.0]butane skeletons (8) (8\% yield) (Fig. 1c). Disilene $\mathbf{8}$ is the dimer of $\mathrm{Si}_{4} \mathrm{BBY}\left(\mathbf{1}^{\prime}\right)$, which is an isomer of $\mathbf{1}$. After keeping the mixture for $48 \mathrm{~h}$ at room temperature, 4 was obtained in $78 \%$ yield, indicating the isomerization of 8 to 4 . Disilene 8 was isolated as deep blue crystals during the reaction and its structure 

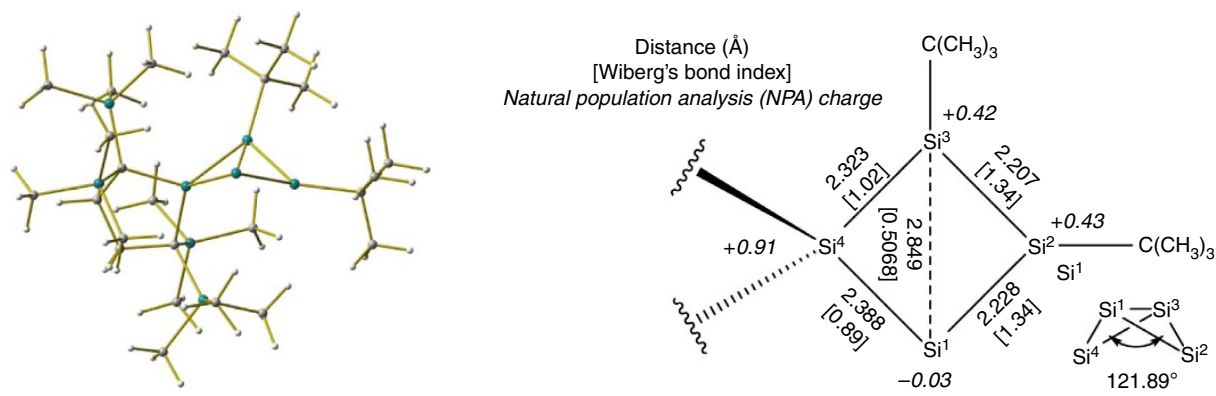

b
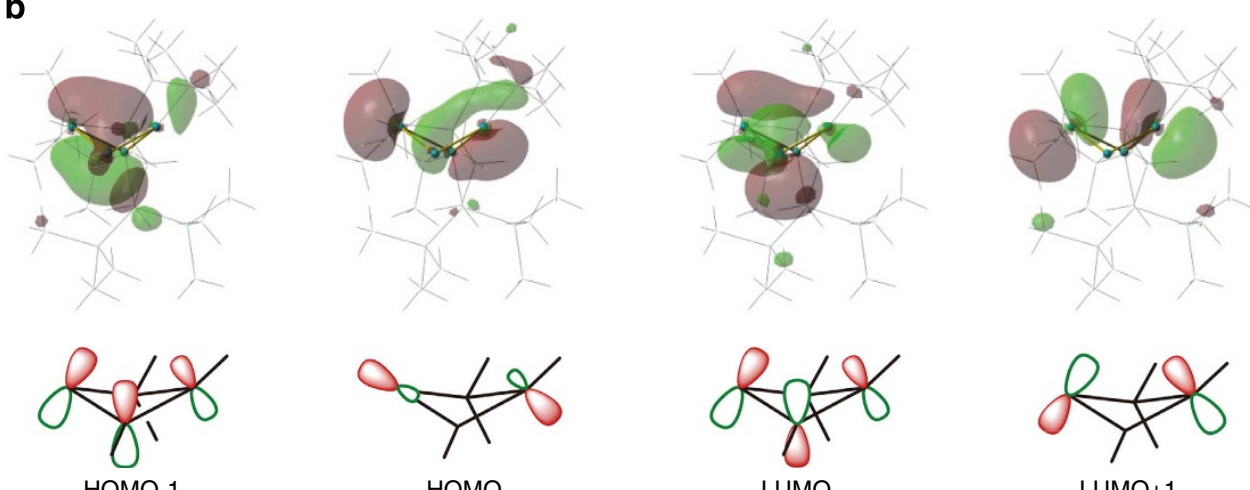

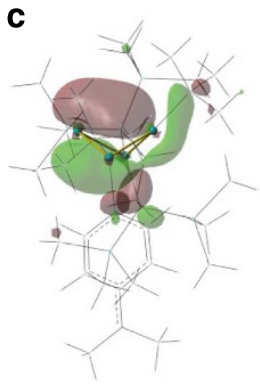

HOMO-1

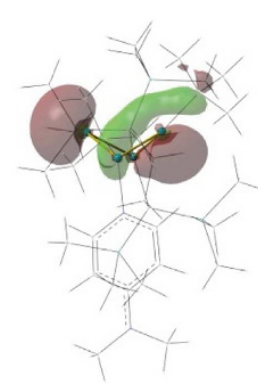

HOMO

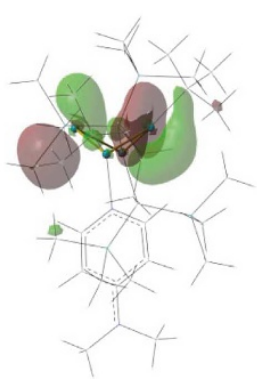

LUMO+2

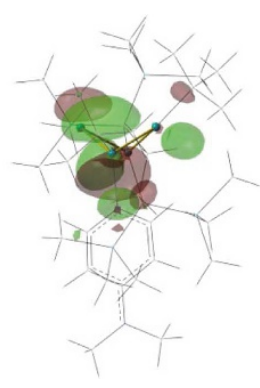

LUMO+3

d

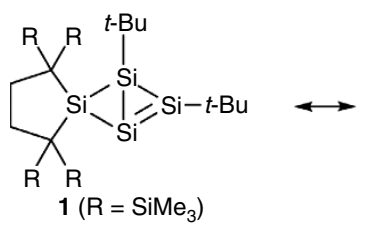

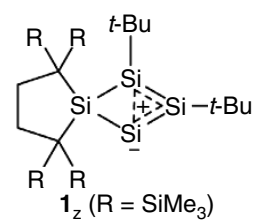

Figure 3 | Electronic structures of $\mathbf{1}$ and 1.DMAP. (a) Optimized structure of $\mathbf{1}\left(\mathbf{1}_{\mathrm{opt}}\right)$ and selected bond lengths, Wiberg bond indices and the natural charges of $\mathbf{1}_{\text {opt }}$ at the M06-2X/6-31G(d) level. (b) Frontier Kohn-Sham orbitals of $\mathbf{1}_{\text {opt }}$ at the M06-2X/6-31G(d) level. (c) Frontier Kohn-Sham orbitals of $\mathbf{1} \cdot \mathrm{DMAP}_{\text {opt }}$. LUMO and LUMO +1 of $\mathbf{1} \cdot \mathrm{DMAP}_{\mathrm{opt}}$ are the anti-bonding $\pi$-orbitals of pyridine moiety in DMAP. (d) Important canonical structures of $\mathbf{1}$.

was determined by XRD analysis, NMR spectroscopy (Fig. 2d; for details, see Supplementary Information). The results indicate the formation of both $\mathbf{1}$ and $\mathbf{1}^{\prime}$ by the reaction of $\mathbf{1} \cdot \mathrm{DMAP}$ with $\mathrm{BPh}_{3}$, equilibrium between $\mathbf{1}$ and $\mathbf{1}^{\prime}$ (Fig. 1d) and the dissociation of disilene $\mathbf{8}$ into $\mathbf{1}^{\prime}$. These are supported by the reaction of disilene 8 with $\mathrm{SiCl}_{4}$ and DMAP affording a $\mathrm{SiCl}_{4}$ adduct of $\mathbf{1}^{\prime}(\mathbf{9})$ and a DMAP adduct of $\mathbf{1}$ (1.DMAP) (Fig. 1e), respectively.

The facile isomerization between $\mathbf{1}$ and $\mathbf{1}^{\prime}$ was supported by theoretical calculations. The $\mathrm{Si}_{4} \mathrm{BBY}\left(\mathbf{1}^{\prime}\right.$ opt $)$ was optimized as the local minimum at the M06-2X/6-31 G(d) level and $\mathbf{1}_{\text {opt }}^{\prime}$ is lower in energy by $11.8 \mathrm{~kJ} \mathrm{~mol}^{-1}(298 \mathrm{~K})$ than $\mathbf{1}_{\text {opt }}$. Similar relative stability for the parent $\mathrm{Si}_{4} \mathrm{H}_{4}$ system has been theoretically predicted previously ${ }^{20,21}$. A concerted pathway involving the 1,2migration of $\mathrm{SiR}_{2}^{\mathrm{H}}$ unit from $\mathrm{Si} 1$ to $\mathrm{Si} 2$ in 1 was predicted for the isomerization of $\mathbf{1}_{\text {opt }}$ to $\mathbf{1}_{\text {opt }}^{\prime}$ and the calculated Gibbs energy of activation $(298 \mathrm{~K})$ for the isomerization was $69.6 \mathrm{~kJ} \mathrm{~mol}^{-1}$ $\left(\mathbf{1}_{\text {opt }}^{\prime} \rightarrow \mathbf{1}_{\text {opt }}\right)$, which is enough for the reversible isomerization at room temperature to proceed. Although $\mathbf{1}_{\text {opt }}^{\prime}$ is more stable than $\mathbf{1}_{\text {opt }}$, the coordination of DMAP to $\mathbf{1}_{\mathrm{opt}}$ $\left(\Delta G_{298 \mathrm{~K}}=-4.0 \mathrm{~kJ} \mathrm{~mol}^{-1}\right)$ is less exergonic than that for $\mathbf{1}_{\mathrm{opt}}$ $\left(\Delta G_{298 \mathrm{~K}}=-39.4 \mathrm{~kJ} \mathrm{~mol}^{-1}\right)$ probably because of the reduced Lewis acidity of $\mathbf{1}^{\prime}$ resulting from the donation of bridgehead $\mathrm{Si}-\mathrm{Si}$ bond electrons to the vacant $3 p$ orbitals of two-coordinate silylene centre. These results are consistent with the observation and isolation of $\mathbf{1}$.DMAP instead of $\mathbf{1}^{\prime}$.DMAP.

The formation of $\mathbf{4}$ as the final product in the reaction of 1.DMAP with $\mathrm{BPh}_{3}$ and the facile dissociation of $\mathbf{8}$ were also supported by theoretical calculations. The optimized structures of 
4 and 8 calculated at the M06-2X level ( $\mathbf{4}_{\text {opt }}$ and $\mathbf{8}_{\text {opt }}$, respectively, see Supplementary Figs 43 and 44) reproduced well structural characteristics of $\mathbf{4}$ and $\mathbf{8}$ as determined by XRD analyses. Dimer $\mathbf{4}_{\text {opt }}$ was $53.5 \mathrm{~kJ} \mathrm{~mol}^{-1}$ more stable than $\mathbf{8}_{\text {opt }}$ and the dimerization of $\mathbf{1}_{\text {opt }}$ into $\mathbf{4}_{\text {opt }}$ was calculated to be considerably exergonic $\left(\Delta G_{298 \mathrm{~K}}=-106.4 \mathrm{~kJ} \mathrm{~mol}^{-1}\right)$ compared with that of $\mathbf{1}^{\prime}{ }_{\text {opt }}$ into $\mathbf{8}_{\text {opt }}\left(\Delta G_{298 \mathrm{~K}}=-52.9 \mathrm{~kJ} \mathrm{~mol}^{-1}\right)$. The calculated bond dissociation enthalpy of the $\mathrm{Si}=\mathrm{Si}$ bond of disilene $\mathbf{8}_{\text {opt }}, 108.5 \mathrm{~kJ} \mathrm{~mol}^{-1}$, was much lower than that of tetrasilyldisilene $\left(\mathrm{Me}_{3} \mathrm{Si}\right)_{2} \mathrm{Si}=$ $\mathrm{Si}\left(\mathrm{SiMe}_{3}\right)_{2} \quad\left(330.6 \mathrm{~kJ} \mathrm{~mol}^{-1}\right)$ at the M06-2X/6-311G(d) level (see Supplementary Tables 10 and 11), but close to that of $\left(\mathrm{Me}_{5} \mathrm{C}_{5}\right)\left[\left(\mathrm{Me}_{3} \mathrm{Si}\right)_{2} \mathrm{~N}\right] \mathrm{Si}=\mathrm{Si}\left[\mathrm{N}\left(\mathrm{SiMe}_{3}\right)_{2}\right]\left(\mathrm{C}_{5} \mathrm{Me}_{5}\right) \quad\left(97.1 \mathrm{~kJ} \mathrm{~mol}^{-1}\right.$, at the RI-BP86/TZVP level), which dissociates into the corresponding silylene in solution ${ }^{36}$. The relatively low bond dissociation enthalpy of $\mathbf{8}_{\text {opt }}$ can be mainly attributed to the stabilization of $\mathbf{1}^{\prime}{ }_{\text {opt }}$ by the donation of bridgehead $\mathrm{Si}-\mathrm{Si}$ bond electrons to the vacant orbital of two-coordinate silicon centre similar to the $\pi$-donation of nitrogen atoms in amino-substituted silylenes. Although other multistep isomerization routes from $\mathbf{8}$ to 4 or the contribution of DMAP that can accelerate the dissociation of the $\mathrm{Si}=\mathrm{Si}$ double bond may not be ruled out, a possible mechanism for the formation of $\mathbf{4}$ from $\mathbf{8}$ can involve the facile dissociation of $\mathbf{8}$ to $\mathbf{1}^{\prime}$ followed by the isomerization of $\mathbf{1}^{\prime}$ to $\mathbf{1}$ and the dimerization of $\mathbf{1}$ to afford 4 .

\section{Discussion}

A heavy analogue of the smallest bridgehead alkene, $\mathrm{Si}_{4} \mathrm{BBE} 1$ was successfully synthesized by coordinating to a Lewis base (1.DMAP) and their electronic structure was revealed. The elimination of DMAP from 1.DMAP afforded a mixture of dimers of $\mathrm{Si}_{4} \mathrm{BBE}$ and $\mathrm{Si}_{4} \mathrm{BBY}$, compounds 4 and $\mathbf{8}$. The facile isomerization between compound $\mathbf{1}$ and its isomer $\mathrm{Si}_{4} \mathrm{BBY} \mathbf{1}^{\prime}$ was confirmed both experimentally and theoretically. Synthesis and reactions of $\mathrm{Si}_{4} \mathrm{BBE} 1$ in this study can be regarded also as an example of contraction and expansion of unsaturated molecular silicon clusters ${ }^{37-41}$ (termed siliconoids by Scheschkewitz and colleagues ${ }^{37}$ ), which have received much attention as possible intermediates of vapour deposition of elemental silicon ${ }^{42,43}$. Transformation via elimination of silylene and/or skeletal isomerization may be a fascinating growth route of well-defined silicon clusters showing unique functions.

\section{Methods \\ General methods. General procedure, materials, experimental details, X-ray analysis and theoretical study in this article are shown in Supplementary Methods. For NMR spectra, Oak Ridge Thermal Ellipsoid Plot (ORTEP) drawings and cal- culation results of the compounds in this article, see Supplementary Figs 1-31, Supplementary Figs 32-38, Supplementary Figs 39-50 and Supplementary Tables 1-13, respectively.}

Thermolysis of tricyclo[2.1.0.0 $\mathbf{1}^{\mathbf{1} 3}$ ]pentasilane 2. To a Schlenk tube $(30 \mathrm{ml})$ equipped with a magnetic stir bar, tricyclo[2.1.0.0 $\left.{ }^{1,3}\right]$ pentasilane $2(27.5 \mathrm{mg}$, $0.0291 \mathrm{mmol})$ and benzene $(3 \mathrm{ml})$ were added. The reaction mixture was heated at $40^{\circ} \mathrm{C}$ for $10 \mathrm{~h}$ and then benzene was removed in vacuo. Recrystallization of the reaction mixture from hexane at $-30^{\circ} \mathrm{C}$ afforded pentacyclo $\left[5 \cdot 1 \cdot 0.0^{1,6} .0^{2,5} \cdot 0^{3,5}\right]$ octasilane 4 as orange crystals $(10.2 \mathrm{mg}, 0.00893 \mathrm{mmol})$ in $61 \%$ yield. mp: $164{ }^{\circ} \mathrm{C}$ (decomposition); ${ }^{1} \mathrm{H}$ NMR (400 MHz, $\left.\mathrm{C}_{6} \mathrm{D}_{6}\right): \delta 0.42\left(\mathrm{~s}, 18 \mathrm{H}, \mathrm{SiMe}_{3}\right), 0.44(\mathrm{~s}, 18 \mathrm{H}$, $\left.\mathrm{SiMe}_{3}\right), 0.485$ (s, 18H, SiMe $), 0.491\left(\mathrm{~s}, 18 \mathrm{H}, \mathrm{SiMe}_{3}\right), 1.51$ (s, 18H, $t$-Bu), 1.54 $(\mathrm{s}, 18 \mathrm{H}, t-\mathrm{Bu}), 1.92-2.20\left(\mathrm{~m}, 8 \mathrm{H}, \mathrm{CH}_{2}\right) ;{ }^{13} \mathrm{C}$ NMR $\left(100 \mathrm{MHz}, \mathrm{C}_{6} \mathrm{D}_{6}\right): \delta 4.39$ $\left(\mathrm{SiMe}_{3}\right), 5.16\left(\mathrm{SiMe}_{3}\right), 5.23\left(\mathrm{SiMe}_{3}\right), 5.58\left(\mathrm{SiMe}_{3}\right), 14.2(\mathrm{C}), 17.4(\mathrm{C}), 25.0(\mathrm{C})$, $27.4(\mathrm{C}), 32.5\left(\mathrm{C}\left(\mathrm{CH}_{3}\right)_{3}\right), 34.7\left(\mathrm{CH}_{2}\right), 35.0\left(\mathrm{C}\left(\mathrm{CH}_{3}\right)_{3}\right), 36.8\left(\mathrm{CH}_{2}\right) ;{ }^{29} \mathrm{Si} \mathrm{NMR}$ $\left(79 \mathrm{MHz}, \mathrm{C}_{6} \mathrm{D}_{6}\right): \bar{\delta}-26.8(\mathrm{Si}),-18.4(\mathrm{Si}-t-\mathrm{Bu}),-5.48(\mathrm{Si}-t-\mathrm{Bu}), 3.98\left(\mathrm{SiMe}_{3}\right)$, $4.22\left(\mathrm{SiMe}_{3}\right), 4.33\left(\mathrm{SiMe}_{3}\right), 4.50\left(\mathrm{SiMe}_{3}\right), 24.6\left(\mathrm{Si}_{-} \mathrm{R}_{2}^{\mathrm{H}}\right)$; HRMS (APCI) $(\mathrm{m} / z)$ : calcd for $\mathrm{C}_{48} \mathrm{H}_{116} \mathrm{Si}_{16}, 1,140.5380$; found, $1,140.5392$; ultraviolet-visible spectra (in hexane): $\lambda_{\max }$ (E) $370 \mathrm{~nm}$ (sh, 5,700), $329 \mathrm{~nm}$ (sh, 15,000), $268 \mathrm{~nm}$ (61,000); analysis (calcd, found for $\left.\mathrm{C}_{48} \mathrm{H}_{116} \mathrm{Si}_{16}\right)$ : C $(50.45,50.59), \mathrm{H}(10.23,10.31)$.

Reaction of tricyclo[2.1.0.0 $0^{1,3}$ pentasilane 2 with DMAP. To a Schlenk tube $(30 \mathrm{ml})$ equipped with a magnetic stir bar, tricyclo[2.1.0.0. $\left.{ }^{1,3}\right]$ pentasilane 2
(142.5 mg, $0.151 \mathrm{mmol})$, DMAP (140.8 $\mathrm{mg}, 1.152 \mathrm{mmol})$ and benzene $(10 \mathrm{ml})$ were added. The reaction mixture was heated at $40{ }^{\circ} \mathrm{C}$ for $5 \mathrm{~h}$ and then benzene was removed in vacuo. Recrystallization of the reaction mixture from hexane at $-35^{\circ} \mathrm{C}$ afforded a mixture of DMAP adduct 1.DMAP and excess DMAP. Recrystallization of the resulting reaction mixture from benzene at room temperature afforded pure 1.DMAP as orange crystals $(92.8 \mathrm{mg}, 0.134 \mathrm{mmol}$ ) in $89 \%$ yield. The single crystals of 1.DMAP suitable for XRD study were obtained by recrystallization from benzene at room temperature. NMR spectra were measured in the presence of a slight excess of DMAP.

mp: $147^{\circ} \mathrm{C} ;{ }^{1} \mathrm{H}$ NMR $\left(500 \mathrm{MHz}, \mathrm{C}_{6} \mathrm{D}_{6}\right): \delta 0.03$ (s, 9H, $\left.\mathrm{SiMe}_{3}\right), 0.38$ (s, 9H, $\mathrm{SiMe}_{3}$ ), 0.61 (s, 9H, $\mathrm{SiMe}_{3}$ ), 0.83 (s, 9H, $\mathrm{SiMe}_{3}$ ), 1.48 (s, 9H, $\left.t-\mathrm{Bu}\right), 1.62$ (s, 9H, $t$ - $\mathrm{Bu}$ ), $1.88\left(\mathrm{~s}, 6 \mathrm{H}, \mathrm{Me}_{2} \mathrm{~N}\right), 2.26-2.41\left(\mathrm{~m}, \mathrm{CH}_{2}\right.$ (overlapped with the Me of free DMAP)), 2.24 (the Me of free DMAP), $5.52(d, J=6.9 \mathrm{~Hz}, 2 \mathrm{H}, \mathrm{CH}$ (pyridyl)), 6.11 (the $\mathrm{CH}$ of free DMAP), 7.70-8.60 (brs, $2 \mathrm{H}, \mathrm{CH}$ (pyridyl)), 8.48 (the $\mathrm{CH}$ of free DMAP); ${ }^{13} \mathrm{C}$ NMR $\left(125 \mathrm{MHz}, \mathrm{C}_{6} \mathrm{D}_{6}\right): \delta 4.88\left(\mathrm{SiMe}_{3}\right), 5.06\left(\mathrm{SiMe}_{3}\right), 5.23\left(\mathrm{SiMe}_{3}\right)$, $5.81\left(\mathrm{SiMe}_{3}\right), 9.09(\mathrm{C}), 15.5(\mathrm{C}), 22.6(\mathrm{C}), 26.3(\mathrm{C}), 32.1\left(\mathrm{C}\left(\mathrm{CH}_{3}\right)\right), 34.8\left(\mathrm{C}^{\left(\mathrm{CH}_{3}\right)}\right)$, $35.1\left(\mathrm{CH}_{2}\right), 35.9\left(\mathrm{CH}_{2}\right), 105.7(\mathrm{CH}), 155.7(\mathrm{CH}) ;{ }^{29} \mathrm{Si} \mathrm{NMR}\left(\overline{99} \mathrm{MHz}, \mathrm{C}_{6} \mathrm{D}_{6}\right): \bar{\delta} 1.16$ $\left(\mathrm{SiMe}_{3}\right), 2.62\left(\mathrm{SiMe}_{3}\right), 4.23\left(\mathrm{SiMe}_{3}\right), 4.41\left(\mathrm{SiMe}_{3}\right),-79.8(\mathrm{Si}-t-\mathrm{Bu}),-84.5$ $(\mathrm{Si}-t-\mathrm{Bu}), 13.3\left(\mathrm{Si}_{-} \mathrm{R}_{2}^{\mathrm{H}}\right) ;{ }^{13} \mathrm{C} \mathrm{CP} / \mathrm{MAS} \mathrm{NMR}(201 \mathrm{MHz}): \delta 4.42,6.28,9.11,16.0$, $24.3,26.5,32.6,35.5,41.4,105.4,107.2,146.7,150.4,156.5 ;{ }^{29} \mathrm{Si} \mathrm{CP} / \mathrm{MAS}$ NMR $(159 \mathrm{MHz}): \delta 1.41\left(\mathrm{SiMe}_{3}\right), 2.87\left(\mathrm{SiMe}_{3}\right), 3.36\left(\mathrm{SiMe}_{3}\right), 5.07\left(\mathrm{SiMe}_{3}\right),-79.3$ $(\mathrm{Si}-t-\mathrm{Bu}), 7.20\left(\mathrm{Si}_{-} \mathrm{R}_{2}{ }_{2}\right), 78.2(\mathrm{Si}-t-\mathrm{Bu})$; HRMS (APCI) $(\mathrm{m} / z):\left([\mathrm{M}]^{+}\right.$was missing but $\left[\mathrm{M}+\mathrm{H}_{3} \mathrm{O}^{+}\right]$was found.) calcd for $\mathrm{C}_{31} \mathrm{H}_{71} \mathrm{~N}_{2} \mathrm{OSi}_{8}, 711.3715$; found, 711.3718; analysis (calcd, found for $\mathrm{C}_{31} \mathrm{H}_{68} \mathrm{~N}_{2} \mathrm{Si}_{8}$ ): $\mathrm{C}(53.68,53.35), \mathrm{H}(9.88,9.72), \mathrm{N}(4.04$, 4.17). In the ${ }^{13} \mathrm{C}$ NMR spectrum in $\mathrm{C}_{6} \mathrm{D}_{6}$ solution, the signals due to the $\mathrm{CH}_{3}$ and aromatic carbons of coordinating DMAP were not observed. In the ${ }^{29} \mathrm{Si} \mathrm{NMR}$ spectrum, both in the solution and solid states the signal due to two-coordinate silicon nuclei (Si1) was not observed.

\section{References}

1. Bredt, J. Über sterische Hinderung in Brückenringen (Bredtsche Regel) und über die meso-trans-Stellung in kondensierten Ringsystemen des Hexamethylens. Justus Liebigs Ann. Chem. 437, 1-13 (1924).

2. Köbrich, G. Bredt compound and the Bredt rule. Angew. Chem. Int. Ed. 12, 464-473 (1973).

3. Keese, R. Methods for the preparation of bridgehead olefins. Angew. Chem. Int. Ed. 1975, 528-538 (1975).

4. Shea, K. J. Recent development in the synthesis, structure and chemistry of bridgehead alkenes. Tetrahedron 36, 1683-1715 (1980).

5. Billups, W. E., Haley, M. M. \& Lee, G.-A. Bicyclo[n.1.0]alkenes. Chem. Rev. 89, 1147-1159 (1989).

6. Dyer, S. F., Kammula, S. \& Shevlin, P. B. Rearrangement of cyclobutenylidene J. Am. Chem. Soc. 99, 8104-8106 (1977).

7. Killmar, H., Carrion, G., Dewar, M. J. S. \& Bingham, R. C. Ground states of molecules. 58. The $\mathrm{C}_{4} \mathrm{H}_{4}$ potential surface. J. Am. Chem. Soc. 103, 5292-5303 (1981).

8. Maier, G. Tetrahedrane and cyclobutadiene. Angew. Chem. Int. Ed. 27, 309-446 (1988).

9. Dinadayalane, T. C., Priyakumar, U. D. \& Sastry, G. N. Exploration of $\mathrm{C}_{6} \mathrm{H}_{6}$ potential energy surface: A computational effort to unravel the relative stabilities and synthetic feasibility of new benzene isomers. J. Phys. Chem. A 108, 11433-11448 (2004).

10. Borst, M. L. G., Ehlers, A. W. \& Lammertsma, K. G3(MP2) ring strain in bicyclic phosphorus heterocycles and their hydrocarbon analogues. J. Org. Chem. 70, 8110-8116 (2005).

11. Cremer, D., Kraka, E., Joo, H., Stearns, J. A. \& Zwier, T. S. Exploration of the potential energy surface of $\mathrm{C}_{4} \mathrm{H}_{4}$ for rearrangement and decomposition reactions of vinylacetylene: A computational study. Part I. Phys. Chem. Chem. Phys. 8, 5304 (2006).

12. Iwamoto, T., Tamura, M., Kabuto, C. \& Kira, M. A stable bicyclic compound with two $\mathrm{Si}=\mathrm{Si}$ double bonds. Science 290, 504-506 (2000).

13. Suzuki, K. et al. A planar rhombic charge-separated tetrasilacyclobutadiene. Science 331, 1306-1309 (2011).

14. Cowley, M. J., Huch, V., Rzepa, H. S. \& Scheschkewitz, D. Equilibrium between a cyclotrisilene and an isolable base adduct of a disilenyl silylene. Nat. Chem. 5, 876-879 (2013).

15. Jana, A., Huch, V. \& Scheschkewitz, D. NHC-stabilized silagermenylidene: a heavier analogue of vinylidene. Angew. Chem. Int. Ed. 52, 12179-12182 (2013)

16. Wang, Y. et al. A stable silicon $(0)$ compound with a $\mathrm{Si}=\mathrm{Si}$ double bond. Science 321, 1069-1071 (2008).

17. Abersfelder, K., White, A. J. P., Rzepa, H. S. \& Scheschkewitz, D. A tricyclic aromatic isomer of hexasilabenzene. Science 327, 564-566 (2010).

18. Tsurusaki, A., Iizuka, C., Otsuka, K. \& Kyushin, S. Cyclopentasilane-fused hexasilabenzvalene. J. Am. Chem. Soc. 135, 16340-16343 (2013).

19. Wiberg, N., Finger, C. M. M. \& Polborn, K. Tetrakis(tri-tert-butylsilyl)tetrahedro-tetrasilane $\left(t \mathrm{Bu}_{3} \mathrm{Si}_{4}\right)_{\mathrm{Si}_{4}}$ : The first molecular silicon compound with a $\mathrm{Si}_{4}$ tetrahedron. Angew. Chem. Int. Ed. 32, 1054-1056 (1993).

20. Yates, B. F. \& Schaefer, III H. F. Tetrasilacyclobutadiylidene: The lowest energy cyclic isomer of singet $\mathrm{Si}_{4} \mathrm{H}_{4}$ ? Chem. Phys. Lett. 155, 563-571 (1989). 
21. Haunschild, R. \& Frenking, G. Tetrahedranes. A theoretical study of singlet $\mathrm{E}_{4} \mathrm{H}_{4}$ molecules (E = C-Pb and B-Tl). Mol. Phys. 107, 911-922 (2009).

22. Sekiguchi, A., Matsuno, T. \& Ichinohe, M. The homocyclotrisilenylium ion: a free silyl cation in the condensed phase. J. Am. Chem. Soc. 122, 11250-11251 (2000).

23. Iwamoto, T. et al. Anthryl-substituted trialkyldisilene showing distinct intramolecular charge-transfer transition. J. Am. Chem. Soc. 131, 3156-3157 (2009).

24. Scheschkewitz, D. A molecular silicon cluster with a "naked" vertex atom. Angew. Chem. Int. Ed. 44, 2954-2956 (2005).

25. Kira, M., Ishida, S., Iwamoto, T. \& Kabuto, C. The first isolable dialkylsilylene. J. Am. Chem. Soc. 121, 9722-9723 (1999).

26. Leszczynska, K. et al. Reversible base coordination to a disilene. Angew. Chem. Int. Ed. 51, 6785-6788 (2012).

27. Kaftory, M., Kapon, M. \& Botoshansky, M. in The Chemistry of Organic Silicon Compounds Vol. 2 (eds Rappoport, Z. \& Apeloig, Y.) Ch. 5 181-266 (John Wiley \& Sons, 1998).

28. Jones, R., Williams, D. J., Kabe, Y. \& Masamune, S. The tetrasilabicyclo[1.1.0]butane system: structure of 1,3-di-tert-butyl-2,2,4,4tetrakis(2,6-diethylphenyl)tetrasilabicyclo[1.1.0]butane. Angew. Chem. Int. Ed. Engl. 25, 173-174 (1986).

29. Ueba-Ohshima, K., Iwamoto, T. \& Kira, M. Synthesis, structure, and facile ring flipping of a bicyclo[1.1.0]tetrasilane. Organometallics 27, 320-323 (2008).

30. Wiberg, N., Schuster, H., Simon, A. \& Peters, K. Hexa-tert-butyldisilane - the molecule with the longest Si-Si bond. Angew. Chem. Int. Ed. 25, 79-80 (1986).

31. Okazaki, R. \& West, R. Chemistry of stable disilenes. Adv. Organomet. Chem. 39, 231-273 (1996)

32. Kira, M. \& Iwamoto, T. Progress in the chemistry of stable disilenes. Adv. Organomet. Chem. 54, 73-148 (2006).

33. Ohms, U. \& Guth, H. Die Kristall- und Molekülstruktur von 4Dimethylaminopyridin $\mathrm{C}_{7} \mathrm{H}_{10} \mathrm{~N}_{2}$. Z. Kristal 166, 213-218 (1984).

34. Inoue, S., Ichinohe, M., Yamaguchi, T. \& Sekiguchi, A. A free silylium ion: a cyclotetrasilenylium Ion with allylic character. Organometallics 27, 6056-6058 (2008).

35. Cowley, M. J., Huch, V. \& Scheschkewitz, D. Donor-acceptor adducts of a 1,3-disila-2-oxyallyl zwitterion. Chem. Eur. J. 20, 9221-9224 (2014).

36. Jutzi, P. et al. Reversible transformation of a stable monomeric silicon(II) compound into a stable disilene by phase transfer: experimental and theoretical studies of the system $\left\{\left[\left(\mathrm{Me}_{3} \mathrm{Si}\right)_{2} \mathrm{~N}\right]\left(\mathrm{Me}_{5} \mathrm{C}_{5}\right) \mathrm{Si}\right\}_{n}$ with $n=1,2$. J. Am. Chem. Soc. 131, 12137-12143 (2009).

37. Abersfelder, K. et al. Contraction and expansion of the silicon scaffold of stable $\mathrm{Si}_{6} \mathrm{R}_{6}$ isomers. J. Am. Chem. Soc. 134, 16008-16016 (2012).

38. Fischer, G. et al. $\mathrm{Si}_{8}\left(\mathrm{Si}_{\mathrm{Bu}}\right)_{6}$ : a hitherto unknown cluster structure in silicon chemistry. Angew. Chem. Int. Ed. 44, 7884-7887 (2005).
39. Nied, D., Köppe, R., Klooper, W., Schnöckel, H. \& Breher, F. Synthesis of a pentasilapropellane. Exploring the nature of a stretched silicon-silicon bond in a nonclassical molecule. J. Am. Chem. Soc. 132, 10264-10265 (2010).

40. Abersfelder, K., White, A. J. P., Berger, R. J., Rzepa, H. S. \& Scheschkewitz, D. A stable derivative of the global minimum on the $\mathrm{Si}_{6} \mathrm{H}_{6}$ potential energy surface. Angew. Chem. Int. Ed. 50, 7936-7939 (2011).

41. Ishida, S., Otsuka, K., Toma, Y. \& Kyushin, S. An organosilicon cluster with an octasilacuneane core: a missing silicon cage motif. Angew. Chem. Int. Ed. 52, 2507-2510 (2013).

42. Lyon, J. T. et al. Structure of silicon cluster cations in the gas phase. J. Am Chem. Soc. 131, 1115-1121 (2009).

43. Haertelt, M. et al. Gas-phase structures of neutral silicon clusters. J. Chem. Phys. 136, 064301 (2012)

\section{Acknowledgements}

This work was supported by JSPS KAKENHI grant number 25248010 (T.I.), 25708004 and 25620020 (S.I.), and MEXT KAKENHI grant number 24109004 (T.I.) (Grant-in-Aid for Scientific Research on Innovative Areas 'Stimuli-responsive Chemical Species')

\section{Author contributions}

T.I., N.A. and S.I. designed the experiments. N.A. synthesized and characterized all the compounds. N.A. and S.I. conducted XRD analysis. T.I. performed theoretical calculations. T.I., N.A. and S.I. analysed the data and wrote the manuscript

\section{Additional information}

Accession codes: The X-ray crystallographic coordinates for structures reported in this study have been deposited at the Cambridge Crystallographic Data Centre (CCDC), under deposition numbers CCDC 1007442 (1.DMAP), CCDC 1007443 (2.(benzene) $)_{0.5}$ ), CCDC 1007444 (2)(2,3-dimethy-1,3-butadiene) $)_{0.5}$ ), CCDC 1007445 (4)(benzene)), CCDC 1007446 (7), CCDC 1007447 (8) and CCDC 1007448 (9). These data can be obtained free of charge from The Cambridge Crystallographic Data Centre via www.ccdc.cam.ac.uk/data_request/cif.

Supplementary Information accompanies this paper at http://www.nature.com/ naturecommunications

Competing financial interests: The authors declare no competing financial interests.

Reprints and permission information is available online at http://npg.nature.com/ reprintsandpermissions

How to cite this article: Iwamoto, T. et al. A heavy analogue of the smallest bridgehead alkene stabilized by a base. Nat. Commun. 5:5353 doi: 10.1038/ncomms6353 (2014). 